\title{
GMR
}

\section{CYP1A2-163C/A (rs762551) polymorphism and bladder cancer risk: a case-control study}

\author{
Y.L. Song ${ }^{1,2}$, L. Wang ${ }^{2}$, J.C. Ren ${ }^{1}$ and Z.H. Xu ${ }^{1}$ \\ ${ }^{1}$ Department of Urology, Qilu Hospital, Shandong University, Jinan, China \\ ${ }^{2}$ Department of Urology, Zaozhuang Municipal Hospital, Zaozhuang, China
}

Corresponding author: Z.-H. Xu

E-mail: xuzhonghuaqlurol@126.com

Genet. Mol. Res. 15 (2): gmr.15026298

Received July 24, 2015

Accepted November 10, 2015

Published April 26, 2016

DOI http://dx.doi.org/10.4238/gmr.15026298

\begin{abstract}
To date, no study has investigated the association between CYP1A2-163C/A polymorphism and bladder cancer risk in a Chinese population. Here, we extracted genomic DNA from peripheral white blood cells, and differentiated CYP1A2 alleles by polymerase chain reaction-based restriction fragment length polymorphism methods. Differences in genotype frequencies between the cases and controls were evaluated using a chi-square test. The odds ratio (OR) and its 95\% confidence interval (CI) were calculated using an unconditional logistic regression model. This revealed that the $-163 \mathrm{~A}$ allele was present at a significantly increased frequency in bladder cancer patients compared to healthy controls $(44.10$ vs $22.25 \%, \mathrm{P}<0.001)$. The prevalence of CC genotype, CA genotype, and AA genotype was 34.91, 41.98, and $23.11 \%$ in bladder cancer patients, and 64.00, 27.50, and 8.5\% in the controls, respectively. Therefore, significant differences in the frequencies of -163 genotypes were found between bladder cancer patients and controls $(\mathrm{P}<0.001)$. We found that the AA genotype was significantly associated with increased bladder cancer risk $(\mathrm{OR}=3.72$; $95 \% \mathrm{CI}=1.55-7.16 ; \mathrm{P}=0.02)$, and the $-163 \mathrm{~A}$ carriers were at increased risk of bladder cancer in a multivariate $\mathrm{COX}$ regression model $(\mathrm{OR}=$ $4.89,95 \% \mathrm{CI}=2.78-10.87, \mathrm{P}=0.01)$. We conclude that the CYP1A2-
\end{abstract}


$163 \mathrm{C} / \mathrm{A}$ polymorphism is associated with increased susceptibility to bladder cancer in the Chinese population.

Key words: CYP1A2; Polymorphism; Bladder cancer; Risk

\section{INTRODUCTION}

Globally, bladder cancer is the seventh most common cancer in men and the seventeenth most common in women. It has a higher incidence in Western countries compared with Asian countries (Murta-Nascimento et al., 2007; Kakehi et al., 2010). Despite the role that environmental factors play in the development of bladder cancer, genetic factors are also closely related to the pathophysiology of the disease (Lin et al., 2006).

Human cytochrome P4501A2 (CYP1A2) is one of the major CYPs in the human liver (Nebert and Dalton, 2006). CYP1A2 is a critical enzyme for the catalysis of 2- and 4-hydroxylations of estrogens (Nebert and Dalton, 2006) and for the metabolism of carcinogens (Eaton et al., 1995). Previously, increased CYP1A2 activity has been associated with a number of environmental factors, including tobacco smoking, occupational exposure, diet, and coffee intake (Chung et al., 2000; Djordjevic et al., 2008). More recently, however, the increased activity has been attributed to specific polymorphisms in the CYP1A2 gene (Pavanello et al., 2005; Gunes et al., 2009).

Previously, many studies have investigated the association between CYP1A2-163C/A polymorphism and cancer risk. Sun et al. (2014) performed a meta-analysis to investigate the association between the CYP1A2-163C/A polymorphism and cancer risk under different inheritance models. Overall, a significant association was observed between CYP1A2-163C/A polymorphism and cancer risk when all the eligible studies were pooled into the meta-analysis (dominant model: $\mathrm{OR}=1.08,95 \% \mathrm{CI}=1.02-1.15$; heterozygous model: $\mathrm{OR}=1.06,95 \% \mathrm{CI}=$ 1.01-1.12; additive model: $\mathrm{OR}=1.07,95 \% \mathrm{CI}=1.02-1.13$ ). In further stratified and sensitivity analyses, a significantly increased lung cancer risk and significantly decreased bladder cancer risk were associated with the CYP1A2-163C/A polymorphism in Caucasians. However, there has been no study investigating the association between the CYP1A2-163C/A polymorphism and bladder cancer risk in a Chinese population.

\section{MATERIAL AND METHODS}

\section{Study subjects}

The study was approved by the Review Board of Qilu Hospital, Shandong University. Written informed consent was obtained from each participant. The study population consisted of 212 patients with bladder cancer. Patients who had previous cancer, metastasized cancer from other or unknown origin, previous radiotherapy or chemotherapy were excluded. All cases of pathological diagnosis for tumor stage were according to the 2002 International Union Against Cancer tumor-nodes-metastasis classification, and for grade as the World Health Organization in 1973 grading of urothelial papilloma: well differentiated (grade 1, G1), moderately differentiated (grade 2, G2), or poorly differentiated (grade 3, G3).

The control group included 200 healthy subjects who came to the hospital for general health exams. The controls were genetically unrelated cancer-free individuals living in the 
same residential areas, and were frequency matched to the cases on age, gender, smoking status, and alcohol use.

\section{Genotyping}

Venous blood $(10 \mathrm{~mL})$ was collected from each patient into tubes containing $50 \mathrm{mM}$ EDTA, and genomic DNA was isolated with a DNAblood Mini kit, according to the manufacturer instructions. Quality control measures included validation of results by polymerase chain reaction-restriction fragment length polymorphism (PCR-RFLP) genotyping and blind repeat of $10 \%$ of samples for the CYP1A2-163C/A polymorphic site. Briefly for the RFLP analysis, all PCRs $(25 \mu \mathrm{L})$ were performed on a GeneAmp PCR System 9700, with each mastermix comprised of $0.2 \mathrm{mM}$ dNTPs, $1 \mathrm{U}$ Taq polymerase, the appropriate concentration of $\mathrm{MgCl}_{2}$ (1.75 and $1.25 \mathrm{mM}$ ), and $0.4 \mathrm{mM}$ of each primer. About $10 \%$ of the samples were randomly selected to perform repeat assays, and the results were 100\% concordant. Two researchers, blinded to the clinical data, scored the genotypes independently.

\section{Statistical analysis}

Hardy-Weinberg equilibrium (HWE) was carried out by a goodness-of-test for the distribution of genotypic frequencies among the controls. Differences in the distributions of demographic characteristics, selected variables and genotype frequencies between the cases and controls were evaluated using the chi-square test (for categorical variables). The odds ratio (OR) and its $95 \%$ confidence interval $(\mathrm{CI})$ were calculated using an unconditional logistic regression model. All analyses were performed using the SPSS 18.0 software. All statistical tests were two sided and $\mathrm{P}<0.05$ was considered statistically significant.

\section{RESULTS}

\section{Characteristics of the study population}

The key demographic and clinical information for 212 bladder cancer cases and 200 healthy controls are presented in Table 1 . No significant difference in age or gender distribution was observed between cases and controls ( $\chi^{2}$ test, $\mathrm{P}=0.844$ and $\mathrm{P}=0.125$, respectively). Moreover, no significant difference in smoking status or drinking status distribution was observed between cases and controls $\left(\chi^{2}\right.$ test, $\mathrm{P}=0.599$ and $\mathrm{P}=0.367$, respectively, shown in Table 1).

\section{CYP1A2-163C/A genotype frequencies in bladder cancer cases and controls}

The genotype distributions for the CYP1A2-163C/A SNP in controls were in accordance with those predicted from the HWE model $(\mathrm{P}>0.05)$. The allele and genotype frequencies of CYP1A2-163C/A for the cases and controls are presented in Table 2. Frequency of the $-163 \mathrm{~A}$ allele was significantly increased in bladder cancer patients compared to healthy controls (44.10 vs 22.25\%, $\mathrm{P}<0.001)$. The prevalence of CC genotype, CA genotype, and AA genotype was $34.91,41.98$, and $23.11 \%$ in bladder cancer patients, and 64.00, 27.50, and $8.5 \%$ in the controls, respectively. Therefore, significant differences in the frequencies of 
-163 genotypes were found between bladder cancer patients and controls $(\mathrm{P}<0.001$, shown in Table 2).

\begin{tabular}{|c|c|c|c|c|c|}
\hline \multirow[t]{2}{*}{ Variables } & \multicolumn{2}{|c|}{ Bladder cases $(\mathrm{N}=212)$} & \multicolumn{2}{|c|}{ Healthy controls $(\mathrm{N}=200)$} & \multirow[t]{2}{*}{ P value } \\
\hline & $\mathrm{N}$ & $\%$ & $\mathrm{~N}$ & $\%$ & \\
\hline \multicolumn{6}{|l|}{ Age (years) } \\
\hline$\leq 65$ & 89 & 41.98 & 91 & 45.50 & 0.844 \\
\hline$>65$ & 123 & 58.02 & 119 & 59.50 & \\
\hline \multicolumn{6}{|l|}{ Gender } \\
\hline Male & 127 & 59.91 & 135 & 67.50 & 0.125 \\
\hline Female & 85 & 40.09 & 65 & 32.50 & \\
\hline \multicolumn{6}{|l|}{ Smoking status } \\
\hline Never smoker & 13 & 6.13 & 17 & 8.50 & 0.599 \\
\hline Former smoker & 21 & 9.91 & 17 & 8.50 & \\
\hline Current smoker & 178 & 83.96 & 166 & 83.00 & \\
\hline \multicolumn{6}{|l|}{ Alcohol drinking } \\
\hline Never drinker & 34 & 16.04 & 41 & 20.50 & 0.367 \\
\hline Former drinker & 33 & 15.57 & 35 & 17.50 & \\
\hline Current drinker & 145 & 68.40 & 124 & 62.00 & \\
\hline \multicolumn{6}{|l|}{ Tumor grade } \\
\hline Low grade & 87 & 41.04 & - & - & \\
\hline High grade & 125 & 58.96 & - & - & \\
\hline \multicolumn{6}{|l|}{ Tumor stage } \\
\hline NMIBC & 123 & 58.02 & - & - & \\
\hline MIBC & 89 & 41.98 & - & - & \\
\hline
\end{tabular}

$\mathrm{NMIBC}=$ non-muscle-invasive bladder cancer; $\mathrm{MIBC}=$ muscle invasive bladder cancer.

Table 2. CYP1A2-163C/A genotype frequencies in bladder cancer cases and controls.

\begin{tabular}{l|c|c|c|c|c}
\hline \multirow{2}{*}{} & \multicolumn{2}{|c|}{ Bladder cancer cases $(\mathrm{N}=212)$} & \multicolumn{2}{c|}{ Healthy controls $(\mathrm{N}=200)$} & \multirow{2}{*}{ P value } \\
\cline { 2 - 5 } & $\mathrm{N}$ & $\%$ & $\mathrm{~N}$ & $\%$ & \\
\hline CYP1A2 genotype & & 34.91 & 128 & 64.00 & $<0.001$ \\
\hline CC & 74 & 41.98 & 55 & 27.50 & \\
\hline CA & 49 & 23.11 & 17 & 8.50 & \\
\hline AA & & & & & \\
\hline Allele & 237 & 55.90 & 311 & 77.75 & $<0.001$ \\
\hline A & 187 & 44.10 & 89 & 22.25 & \\
\hline
\end{tabular}

\section{CYP1A2-163C/A polymorphisms and susceptibility to bladder cancer}

We found that the AA genotype was significantly associated with increased bladder cancer risk (adjusted $\mathrm{OR}=3.72 ; 95 \% \mathrm{CI}=1.55-7.16 ; \mathrm{P}=0.02$ ). However, the $\mathrm{CA}$ genotype was not significantly associated with bladder cancer risk (adjusted $\mathrm{OR}=1.84 ; 95 \% \mathrm{CI}=0.79$ 3.28; $\mathrm{P}=0.16$ ). We also found that $-163 \mathrm{~A}$ carriers were at increased risk of bladder cancer in a multivariate COX regression model, which was adjusted for age, gender, alcohol intake, and smoking status $(\mathrm{OR}=4.89,95 \% \mathrm{CI}=2.78-10.87, \mathrm{P}=0.01)$. There was no significant association between CYP1A2-163C/A polymorphisms and susceptibility to bladder cancer under both dominant and recessive models $(\mathrm{OR}=2.97,95 \% \mathrm{CI}=0.89-5.11, \mathrm{P}=0.11$ and $\mathrm{OR}$ $=2.45,95 \% \mathrm{CI}=1.55-4.58, \mathrm{P}=0.09$, respectively, shown in Table 3 ). 
Table 3. CYP1A2-163C/A polymorphism and susceptibility to bladder cancer.

\begin{tabular}{|c|c|c|c|c|}
\hline & Patients & Controls & OR $(95 \% \mathrm{CI})^{1}$ & $P$ value \\
\hline \multicolumn{5}{|c|}{ General genotype } \\
\hline $\mathrm{CC}$ & 74 & 128 & 1.00 (Reference) & \\
\hline $\mathrm{CA}$ & 89 & 55 & $1.84(0.79-3.28)$ & 0.16 \\
\hline $\mathrm{AA}$ & 49 & 17 & $3.72(1.55-7.16)$ & 0.02 \\
\hline \multicolumn{5}{|c|}{ Dominant genotype } \\
\hline $\mathrm{CC}$ & 74 & 128 & 1.00 (Reference) & \\
\hline $\mathrm{CA}+\mathrm{AA}$ & 138 & 72 & $2.97(0.89-5.11)$ & 0.11 \\
\hline \multicolumn{5}{|c|}{ Recessive genotype } \\
\hline $\mathrm{CC}+\mathrm{CA}$ & 163 & 183 & 1.00 (Reference) & \\
\hline $\mathrm{AA}$ & 49 & 17 & $2.45(1.55-4.58)$ & 0.09 \\
\hline \multicolumn{5}{|c|}{ Allele frequency } \\
\hline $\mathrm{C}$ & 237 & 311 & 1.00 (Reference) & \\
\hline $\mathrm{A}$ & 187 & 89 & $4.89(2.78-10.87)$ & 0.01 \\
\hline
\end{tabular}

${ }^{1}$ Adjusted for gender, age, smoking status, and drinking status.

\section{DISCUSSION}

Epidemiologic studies have emphasized the significant contribution of food and lifestyle to bladder cancer risk (He and Shui, 2014; Liang et al., 2014). High-fat and low-fiber diets, as well as alcohol, tobacco, and red or processed meat consumption, produce high levels of polycyclic aromatic hydrocarbons and heterocyclic aromatic amines. These procarcinogenic agents are potentially very harmful and may play a key role in the malignant transformation of cells by interacting with DNA (Steinmaus et al., 2000). This risk may be due to carcinogenic polycyclic aromatic hydrocarbons and heterocyclic amines produced when meat is cooked at high temperatures (Wang and Jiang, 2012).

Environmental and genetic factors influence the activity of CYP1A2. Tobacco smoking and consumption of fried and grilled food, coffee and cruciferous vegetables increase CYP1A2 activity in humans (Djordjevic et al., 2008). However, intake of apiaceous-like vegetables and the use of oral contraceptives decrease this activity (Lampe et al., 2000). CYP1A2 activity is also modulated by specific polymorphisms in the CYP1A2 gene (Dobrinas et al., 2011). Polymorphisms located in the 5'-non-coding promoter region [-3860G/A (rs2069514), -2467T/delT (rs3569413)] and in intron 1 [-163C/A (rs762551)] of the CYP1A2 gene modified CYP1A2 activity of smokers, measured by the urinary caffeine metabolic ratio (Ghotbi et al., 2007; Gunes et al., 2009).

Previously, many studies have investigated the association between CYP1A2$163 \mathrm{C} / \mathrm{A}$ polymorphism and the risk of cancer. Sun et al. (2014) performed a meta-analysis to investigate whether CYP1A2-163C/A polymorphism was associated with cancer risk under different inheritance models. Overall, a significant association was observed between CYP1A2-163C/A polymorphism and cancer risk when all the eligible studies were pooled into the meta-analysis (dominant model: $\mathrm{OR}=1.08,95 \% \mathrm{CI}=1.02-1.15$; heterozygous model: $\mathrm{OR}$ $=1.06,95 \% \mathrm{CI}=1.01-1.12$; additive model: $\mathrm{OR}=1.07,95 \% \mathrm{CI}=1.02-1.13)$. In the further stratified and sensitivity analyses, for CYP1A2-163C/A polymorphism, significantly increased lung cancer risk and significantly decreased bladder cancer risk were observed in Caucasians. However, there have been no studies investigating the association between CYP1A2-163C/A polymorphism and bladder cancer risk in a Chinese population.

Here, we found that frequency of the $-163 \mathrm{~A}$ allele was significantly increased frequency in bladder cancer patients compared to healthy controls. The prevalences of CC, 
CA, and AA genotypes were $34.91,41.98$, and $23.11 \%$ in bladder cancer patient; this was significantly different to the frequencies in controls $(64.00,27.50$, and $8.5 \%$, respectively). We found that the AA genotype was significantly associated with increased bladder cancer risk. We also found that $-163 \mathrm{~A}$ carriers were at increased risk of bladder cancer in a multivariate COX regression model, which was adjusted for age, gender, alcohol intake, and smoking status. We suggest that an important next step is to broaden this type of study to larger patient cohorts in order to strengthen our conclusions.

\section{Conflicts of interest}

The authors declare no conflict of interest.

\section{REFERENCES}

Chung WG, Kang JH, Park CS, Cho MH, et al. (2000). Effect of age and smoking on in vivo CYP1A2, flavin-containing monooxygenase, and xanthine oxidase activities in Koreans: determination by caffeine metabolism. Clin. Pharmacol. Ther. 67: 258-266. http://dx.doi.org/10.1067/mcp.2000.104617

Djordjevic N, Ghotbi R, Bertilsson L, Jankovic S, et al. (2008). Induction of CYP1A2 by heavy coffee consumption in Serbs and Swedes. Eur. J. Clin. Pharmacol. 64: 381-385. http://dx.doi.org/10.1007/s00228-007-0438-6

Dobrinas M, Cornuz J, Oneda B, Kohler Serra M, et al. (2011). Impact of smoking, smoking cessation, and genetic polymorphisms on CYP1A2 activity and inducibility. Clin. Pharmacol. Ther. 90: 117-125. http://dx.doi.org/10.1038/clpt.2011.70

Eaton DL, Gallagher EP, Bammler TK and Kunze KL (1995). Role of cytochrome P4501A2 in chemical carcinogenesis: implications for human variability in expression and enzyme activity. Pharmacogenetics 5: 259-274. http://dx.doi. org/10.1097/00008571-199510000-00001

Ghotbi R, Christensen M, Roh HK, Ingelman-Sundberg M, et al. (2007). Comparisons of CYP1A2 genetic polymorphisms, enzyme activity and the genotype-phenotype relationship in Swedes and Koreans. Eur. J. Clin. Pharmacol. 63: 537546. http://dx.doi.org/10.1007/s00228-007-0288-2

Gunes A, Ozbey G, Vural EH, Uluoglu C, et al. (2009). Influence of genetic polymorphisms, smoking, gender and age on CYP1A2 activity in a Turkish population. Pharmacogenomics 10: 769-778. http://dx.doi.org/10.2217/pgs.09.22

$\mathrm{He} \mathrm{H}$ and Shui B (2014). Folate intake and risk of bladder cancer: a meta-analysis of epidemiological studies. Int. J. Food Sci. Nutr. 65: 286-292. http://dx.doi.org/10.3109/09637486.2013.866641

Kakehi Y, Hirao Y, Kim WJ, Ozono S, et al. (2010). Bladder Cancer Working Group report. Jpn. J. Clin. Oncol. 40 (Suppl 1): i57-i64. http://dx.doi.org/10.1093/jjco/hyq128

Lampe JW, King IB, Li S, Grate MT, et al. (2000). Brassica vegetables increase and apiaceous vegetables decrease cytochrome P450 1A2 activity in humans: changes in caffeine metabolite ratios in response to controlled vegetable diets. Carcinogenesis 21: 1157-1162. http://dx.doi.org/10.1093/carcin/21.6.1157

Liang S, Lv G, Chen W, Jiang J, et al. (2014). Citrus fruit intake and bladder cancer risk: a meta-analysis of observational studies. Int. J. Food Sci. Nutr. 65: 893-898. http://dx.doi.org/10.3109/09637486.2014.917151

Lin BK, Clyne M, Walsh M, Gomez O, et al. (2006). Tracking the epidemiology of human genes in the literature: the HuGE Published Literature database. Am. J. Epidemiol. 164: 1-4. http://dx.doi.org/10.1093/aje/kwj175

Murta-Nascimento C, Schmitz-Dräger BJ, Zeegers MP, Steineck G, et al. (2007). Epidemiology of urinary bladder cancer: from tumor development to patient's death. World J. Urol. 25: 285-295. http://dx.doi.org/10.1007/s00345-007-0168-5

Nebert DW and Dalton TP (2006). The role of cytochrome P450 enzymes in endogenous signalling pathways and environmental carcinogenesis. Nat. Rev. Cancer 6: 947-960. http://dx.doi.org/10.1038/nrc2015

Pavanello S, Pulliero A, Lupi S, Gregorio P, et al. (2005). Influence of the genetic polymorphism in the 5'-noncoding region of the CYP1A2 gene on CYP1A2 phenotype and urinary mutagenicity in smokers. Mutat. Res. 587: 59-66. http://dx.doi.org/10.1016/j.mrgentox.2005.08.008

Steinmaus CM, Nuñez S and Smith AH (2000). Diet and bladder cancer: a meta-analysis of six dietary variables. Am. J. Epidemiol. 151: 693-702. http://dx.doi.org/10.1093/oxfordjournals.aje.a010264

Sun WX, Chen YH, Liu ZZ, Xie JJ, et al. (2014). Association between the CYP1A2 polymorphisms and risk of cancer: a meta-analysis. Molecular genetics and genomics: MGG.

Wang C and Jiang H (2012). Meat intake and risk of bladder cancer: a meta-analysis. Med. Oncol. 29: 848-855. http:// dx.doi.org/10.1007/s12032-011-9985-x

Genetics and Molecular Research 15 (2): gmr.15026298

CFUNPEC-RP www.funpecrp.com.br 